\title{
Submitted: Fetal cardiac function by three-dimensional ultrasound Accepted: using 4D-STIC and VOCAL - an update
} 16.10.2019

Published: 31.12.2019

\section{Keywords}

fetal heart, cardiac function, three-dimensional ultrasound, spatio-temporal image correlation, virtual organ computer-aided analysis

\author{
Nathalie Jeanne Bravo-Valenzuela1', Alberto Borges Peixoto², \\ Milene Carvalho Carrilho ${ }^{1}$, Ana Letícia Siqueira Pontes ${ }^{1}$, \\ Caroline Cevante Chagas ${ }^{1}$, Christiane Simioni ${ }^{1}$, \\ Edward Araujo Júnior ${ }^{1}$
}
${ }^{1}$ Department of Obstetrics, Paulista School of Medicine, Federal University of São Paulo (EPM-UNIFESP), São Paulo-SP, Brazil
${ }^{2}$ Department of Obstetrics and Gynecology, Federal University of Triângulo Mineiro (UFTM), Uberaba-MG, Brazil

Correspondence: Prof. Edward Araujo Júnior, PhD, Rua Belchior de Azevedo, 156 apto. 111 Torre Vitoria, São Paulo-SP, Brazil, CEP 05089-030; tel./fax: + 551137965944 , e-mail:araujojred@terra.com.br

DOI: $10.15557 / J o U .2019 .0043$

\begin{abstract}
Three- and four-dimensional (3D/4D) ultrasonography with spatio-temporal image correlation (4D-STIC) allows obtaining fetal cardiac volumes and their static and real-time analysis in multiplanar and rendering modes. Cardiac biometrics and Doppler-echocardiographic parameters for evaluation of fetal heart function, including cardiac output and stroke volume, can be analyzed using M-mode, two-dimensional (2D), and 3D/4D cardiac ultrasound. In recent years, functional echocardiography has been used to study fetuses without a structurally cardiac defect but who are at risk of heart failure due to the presence of extra-cardiac conditions, such as, fetal growth restriction, tumors/masses, twin-to-twin transfusion syndrome, fetal anemia (Rh alloimmunization), congenital infections, or maternal diabetes mellitus. The assessment of cardiac function provides important information on hemodynamic status and can help optimize the best time for delivery and reduce perinatal morbidity and mortality. Since 2003, with the advent of the 4D-STIC software, it is possible to evaluate the fetal heart in multiplanar, and rendering modes. This technology associated with virtual organ computer-aided analysis (VOCAL) enables determining the ventricular volume (end-diastole, end-systole), the stroke-volume, the ejection fraction, and the cardiac output of each ventricle. Since 2004, several studies demonstrated that the 4D-STIC and VOCAL had good reproducibility to measure cardiac volumes This study reviews published studies that evaluated the fetal cardiac function by 3D ultrasound using 4D-STIC and VOCAL software.
\end{abstract}

\section{Introduction}

Congenital heart disease (CHD) occurs in one to two newborns per 100 live births and is an important cause of perinatal morbidity and mortality ${ }^{(1-4)}$. Prenatal screening and diagnosis of anatomical and functional heart malformations are possible by ultrasonography and fetal echocardiography, allowing for planning of delivery and, in some cases, prenatal therapy, favoring the postnatal prognosis of $\mathrm{CHD}^{(5-7)}$.

Cardiac function is routinely evaluated in fetuses with anatomical malformations. In recent years, functional echocardiography has been used to study fetuses with 
a structurally normal heart but who are susceptible to hemodynamic changes due to the presence of extra-cardiac conditions, including, among others, fetal growth restriction, tumors/masses, twin-to-twin transfusion syndrome, fetal anemia (Rh alloimmunization), congenital infections, or maternal diseases such as diabetes mellitus, systemic arterial hypertension, and Graves' disease $\mathrm{e}^{(8-11)}$.

The assessment of cardiac function provides critical information on hemodynamic status and the cardiovascular adaptation of the fetus and can help optimize the best time for delivery and reduce perinatal morbidity and mortality. Various myocardial parameters can be analyzed in combination considering specific applications for different diseases.

The systolic function of the fetal heart can be evaluated by measuring the ejection fraction (EF), shortening fraction $(\mathrm{SF})$, cardiac output (CO), cardiac volume (CV), maximal displacement of the valve ring (tricuspid or mitral), myocardial performance index (MPI), and myocardial strain parameters $^{(8-13)}$. Cardiac function, including SF, CO, and $\mathrm{CV}$, can be analyzed by one-dimensional (M-mode), 2D, and $3 \mathrm{D} / 4 \mathrm{D}$ ultrasound. The measurement of ventricular volumes during diastole and systole by 3D/4D ultrasound combined with virtual organ computer-aided analysis (VOCAL) allows calculating the EF and $\mathrm{CO}$ of each ventricle (left ventricle and right ventricle) and both (combined $\mathrm{CO})^{(14,15)}$.

The objective of this study is to review the published studies that assessed systolic function using 3D ultrasound combined with spatio-temporal image correlation (4D-STIC) and VOCAL.

\section{Analysis of systolic function}

Many techniques are available to evaluate cardiac function in fetuses, including Doppler blood flow, measurement of the heart chambers (cardiac biometrics) and of each interval of the cardiac cycle, $\mathrm{CV}$ by $3 \mathrm{D} / 4 \mathrm{D}$ ultrasound, or the

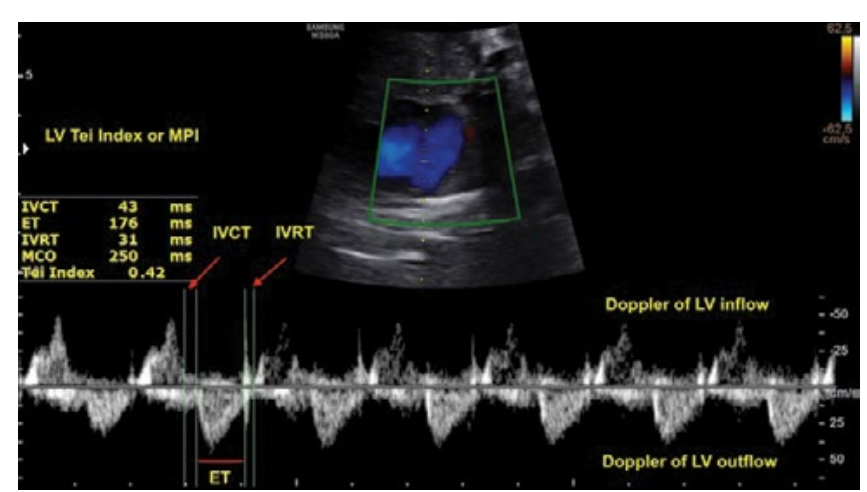

Fig. 1. Myocardial performance index (MPI) or left ventricular Tei index calculated by the formula: $M P I=$ isovolumetric contraction time $(I V C T)+$ isovolumetric relaxation time (IVRT)/ ejection time (ET). The ventricular outflow and inflow values should be obtained by Doppler to measure MPI combination of several parameters. Therefore, MPI, stroke volume (SV), CO, SF, and EF may be used to assess systolic function.

MPI is a quantitative, non-invasive method used for the assessment of systolic and diastolic cardiac function. It is calculated for each ventricle using spectral Doppler and the following formula: isovolumetric contraction time $(\mathrm{ICT})+$ isovolumetric relaxation time (IRT)/ejection time (ET) (Fig. 1). Myocardial dysfunction may lead to prolonged isovolumetric intervals and decreased ET, resulting in increased MPI. MPI values higher than 0.52 were highly sensitive and specific to predict adverse events during pregnancy and the neonatal period ${ }^{(16-19)}$.

The atrioventricular annular movement determined using the M-mode ultrasound/echocardiogram (mitral annular plane systolic excursion [MAPSE] and tricuspid annular plane systolic excursion [TAPSE]) is easy to obtain and has a good correlation with tissue Doppler measurements for evaluating the longitudinal systolic function of the fetal myocardium ${ }^{(20)}$ (Fig. 2 A, $\mathrm{B}$, and $\mathrm{C})$. Moreover, TAPSE can be determined in the 4D-STIC M-mode with good reproducibility, and reference curves for TAPSE by gestational age (GA) have been validated $^{(20-21)}$.

In recent years, the advancements of tissue Doppler with speckle tracking enable the accuracy of the measurements of myocardial strain indexes (strain and strain rate), which are important for assessing left ventricle (LV) function (Fig. 3). Despite the high potential of 2D speckle tracking, its applicability in fetal cardiac analysis needs to be validated ${ }^{(10-13)}$.

SV can be calculated for each ventricle in the 2D mode, multiplying the valve area of the outflow tract by the mean velocity-time integral (VTI) of the ventricular outflow: SV = wr2 $\times$ VTI (Fig. 4). SV can be determined by 3D/4D ultrasonography using the following formula: end-diastolic volume (EDV) - end-systolic volume (ESV) (Fig. 5). The combined $\mathrm{CO}$ can be calculated by multiplying the sum of the SV of the two ventricles by the heart rate $(\mathrm{bpm})(\mathrm{CO}=\mathrm{RV} \mathrm{SV}$ + LV SV $\times$ HR). Similarly to the SV, the CO can be calculated for each ventricle and also increases with GA. The SVs of the LV and right ventricle (RV) are positively correlated with GA, and after 24 weeks of gestation, the RV CO predominates over the LV CO. Several z-scores and percentile curves were developed for $\mathrm{CO}$ as a function of GA using 2D ultrasound ${ }^{(22-26)}$. CO values below the 5 th percentile or below -2.0 are considered low, and $\mathrm{CO}$ values above the 95 th percentile or above +2.0 are considered high in reference curves by GA. The $\mathrm{CO}$ of the fetus may increase in cases of arteriovenous malformations of the central nervous system (Galen's aneurysm), teratomas, and twin-to-twin transfusion syndrome, or decrease in cases of low cardiac contractility, including myocarditis and fetal cardiomyopathy ${ }^{(8,9,26)}$.

The EF reflects the percentage of blood ejected from the ventricles and can be calculated in each ventricle by $3 \mathrm{D}$ ultrasound with 4D-STIC using the following formula: EDV-ESV/EDV. EDV and ESV can be measured by 3D 

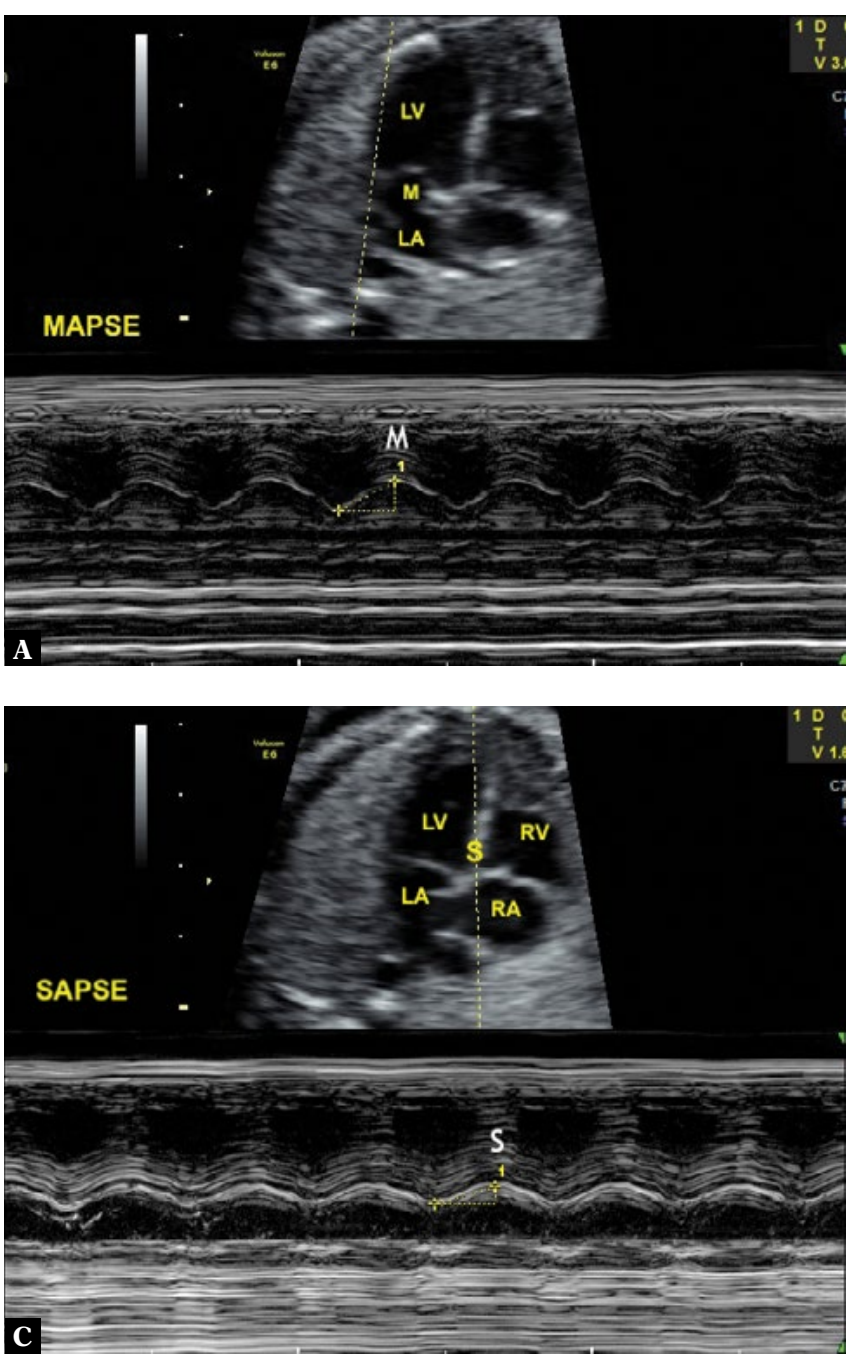

ultrasound using 4D-STIC with VOCAL (Fig. 5). SF is an index that evaluates reduction of ventricular diameter from end-diastole to end-systole. Using the M-mode with 2D and 3D ultrasound (4D-STIC M-mode), the maximum and minimum diameters of each ventricle can be measured in the four-chamber plane. SF can be calculated separately for each ventricle using the following formula: maximal or end-diastolic diameter (EDD) - minimum or end-systolic diameter (ESD)/EDD. SF below $28 \%$ on M-mode and EF below $63 \%$ on $3 \mathrm{D} / 4 \mathrm{D}$ mode without changes by GA are considered altered ${ }^{(27-29)}$.

Assessment of fetal cardiac function by 3D ultrasonography with 4D-STIC

Since 2003, with the advent of the 4D-STIC software, it is possible to evaluate the fetal heart in multiplanar, and rendering modes. This technology, initially described by De Vore et al., allows measuring fetal CVs using a volumetric transducer during a scan of 7.5-15.0 s, with the acquisition of $1502 \mathrm{D}$ images per second. The reconstruction of these images in time-correlated $3 \mathrm{D}$ volumes (4D-STIC) enables simulation of cardiac movements

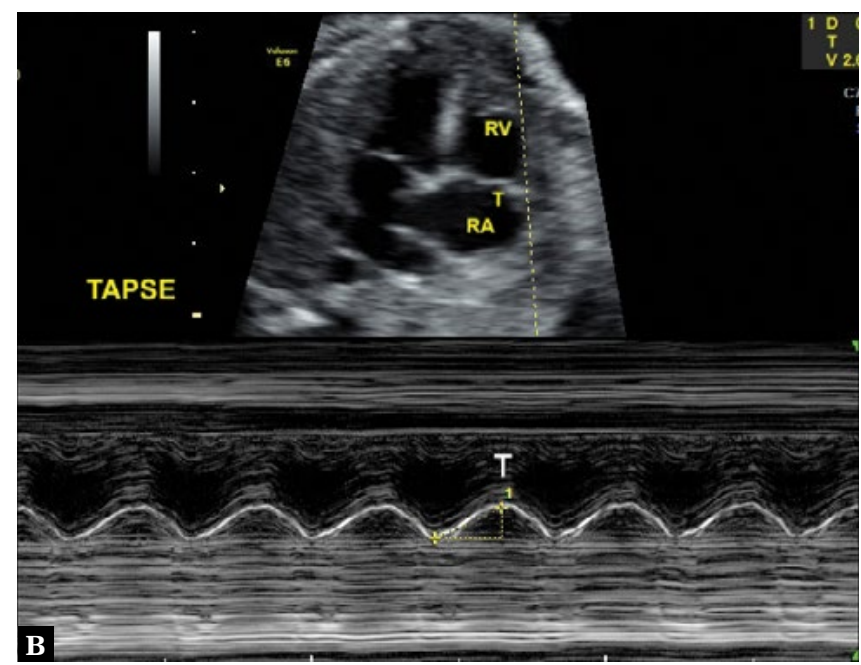

Fig. 2. Evaluation of the atrioventricular annular movement in the unidimensional mode (M-mode) of the echocardiogram. A. MAPSE, mitral annular plane systolic excursion; B. TAPSE, tricuspid annular plane systolic excursion; C. SAPSE, septal annular plane systolic excursion. $L A$ - left atrium; $L V$ - left ventricle; $M$ - mitral valve; $R A$ - right atrium; $R V$ - right ventricle; $S$ - interventricular septum; $T$-tricuspid valve

(cinellop). Moreover, this technique enables anatomical and functional analysis of the fetal heart in the absence of the patient (off-line) and the delivery of CV data using an internet link for analysis in tertiary centers (tele-STIC) (30-34)

The quantification of ventricular volumes during diastole and systole by 4D-STIC and VOCAL enables calculating the ESV, CO, and EF, combined or not with other modalities, including the inversion mode, Color Doppler, and power Doppler ${ }^{(14,15)}$. The 4D-STIC M-mode also allows measuring the EF and SF of the ventricles by determining their end-diastolic and end-systolic diameters, and

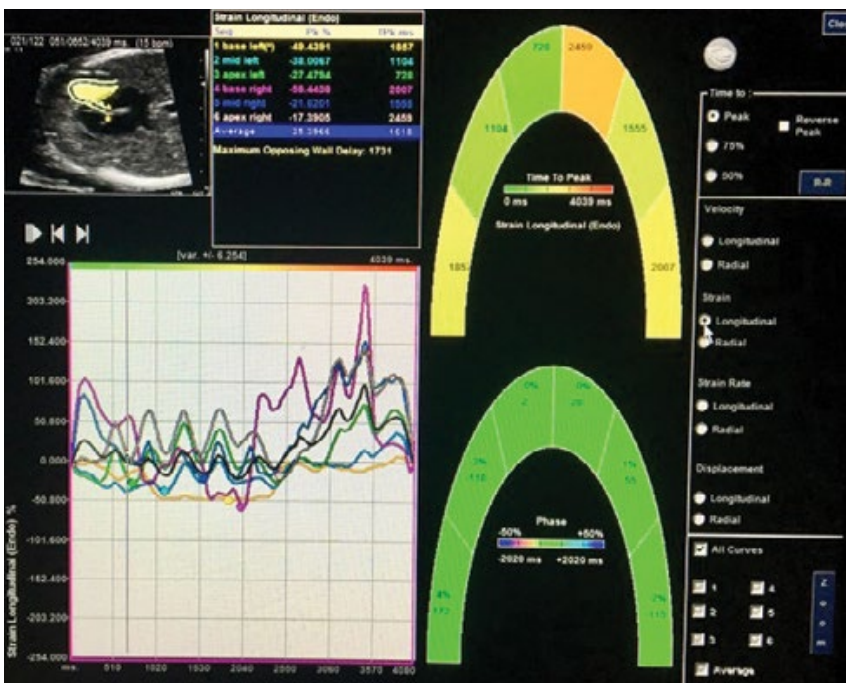

Fig. 3. Analysis of myocardial deformity by speckle tracking, which tracks acoustic markers (speckle) and improves the accuracy of the measurements 

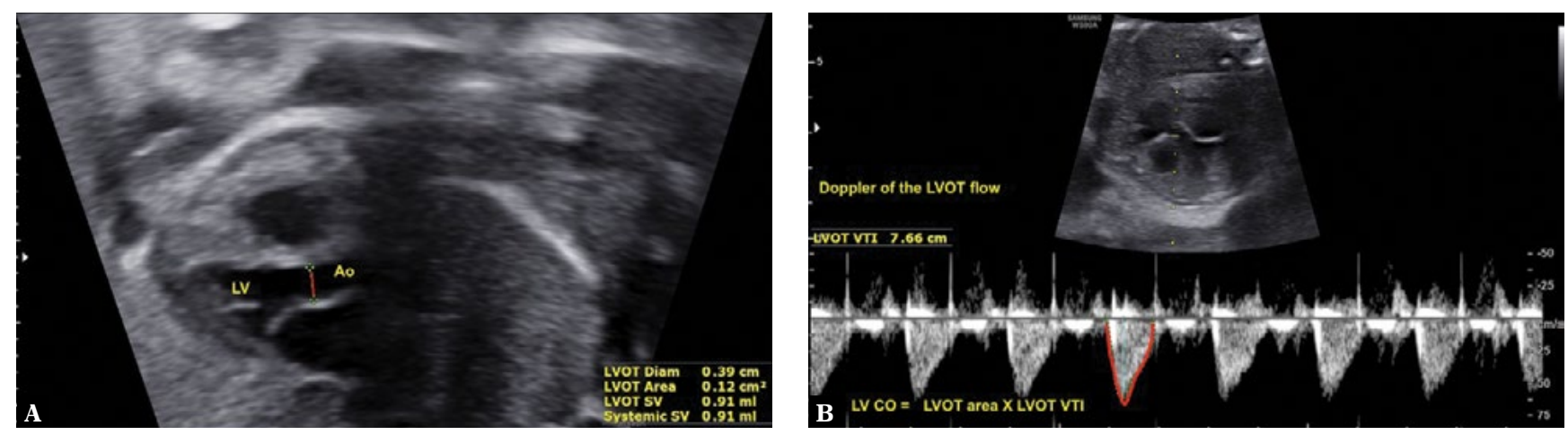

Fig. 4. The stroke volume (SV) can be calculated for each ventricle in the 2D mode by multiplying the valve area of the outflow tract by the mean velocity-time integral (VTI) of the ventricular outflow: $S V=\varpi r 2 \times V T I$. Ao-aorta; LV-left ventricle; LVOT-left ventricle outflow tract

its effectiveness in fetuses with hydrops has also been demonstrated ${ }^{(22)}$

\section{Methods}

For this review, a search strategy was carried out at the PubMed database to identify articles published in English between 2004 and 2019. The objective of this approach was to identify relevant studies on the functional assessment of a human fetal heart by 3D ultrasonography and 4D-STIC and VOCAL. The following MESH terms were used: "fetal heart," "cardiac volumes," and "virtual organ computeraided analysis." A total of 18 articles were found. Only studies that performed functional analyses of the normal fetal heart by 3D ultrasound using 4D-STIC and VOCAL were included in the review. The titles and abstracts of these articles were obtained. Four of the 18 studies were excluded for the following reasons: use of VOCAL in hypoplastic left heart syndrome (one study), use of VOCAL for measuring thymus volume (one study), and use of 4D-STIC without VOCAL (two studies). Three other articles were added after analyzing the selected articles and their references. Consequently, 17 articles were analyzed (Tab. 1).

\section{Measurement of $\mathrm{CO}$ and $\mathrm{EF}$ using 4D-STIC and VOCAL}

Although 4D-STIC was initially used in vivo for the analysis of CHD, Bhat et al. performed the first study to quantify the ventricular mass using 4D-STIC combined with VOCAL. In this study, the obtained values of the chamber volumes were multiplied by the myocardial density $\left(1050 \mathrm{~g} / \mathrm{cm}^{3}\right)$ to determine ventricular mass in mesodiastole. This study was performed in vivo with 90 normal fetuses between 15 and 37 weeks of gestation and in vitro using pulsating balloons, which simulated the four cardiac chambers. There was a positive correlation between the mass of both ventricles and $\mathrm{GA}^{(35)}$.

Rizzo et al. demonstrated that the use of 4D-STIC and VOCAL for measuring ventricular CVs presented a good agreement with 2D Doppler measurements. Messing et al. (2007) acquired cardiac images in mesodiastole using
4D-STIC and VOCAL with inversion mode to quantify ventricular volumes and the EF of fetuses without structural changes. The study included 100 normal fetuses between 20 and 40 weeks of gestation. The results demonstrated that the mean ESV ranged from 0.17 to 1.56 $\mathrm{cm}^{3}$ for the LV and from 0.26 to $2.29 \mathrm{~cm}^{3}$ for the RV. The mean LV-RV SV ratio was 1.4, and the EF ranged from $42.5 \%$ to $86 \%{ }^{(36)}$.

Hamill et al. analyzed 44 fetuses between 19 and 40 weeks of gestation and found good reproducibility in the quantification of CVs by VOCAL, in agreement with previous studies ${ }^{(33,36,37)}$. Molina et al. analyzed SV and CO in 140 normal fetuses between 12 and 34 weeks of gestation using 4D-STIC with VOCAL. The CVs were smaller than those obtained in previous studies in $2 \mathrm{D}$ mode, and there was a positive correlation of SV and $\mathrm{CO}$ with $\mathrm{GA}^{(14)}$.

Uittenbogaard et al. carried out an in vitro study in which small balloons connected to a pump system were used to mimic fetal heart chambers. In this study, 76 fetal CVs were acquired by 4D-STIC using three methods: 3D slice, VOCAL, and VOCAL with inversion mode. These authors concluded that 4D-STIC was a viable and accurate method for calculating volumes from $0.30 \mathrm{~mL}$. In vitro, the $3 \mathrm{D}$ slice method was more accurate, less

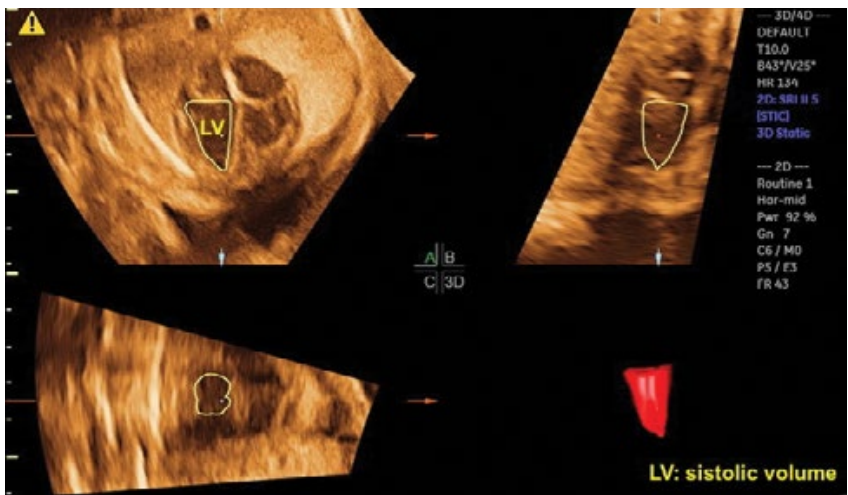

Fig. 5. Measurement of the LV cardiac output and ejection fraction using the 4D-STIC and VOCAL software. LV-left ventricle 
Tab. 1. Studies evaluating ventricular cardiac function - cardiac output, stroke volume, and ejection fraction - using three-dimensional ultrasound with $4 D$-STIC and VOCAL

\begin{tabular}{|c|c|c|c|}
\hline Author & Total number of cases & $\begin{array}{c}\text { Gestational age } \\
\text { (weeks) }\end{array}$ & Conclusion \\
\hline Bhat et al. (2004)(35) & 90 (in vitro) & $15-37$ & There was a positive correlation between ventricular mass and gestational age. \\
\hline Rizzo et al. $(2007)^{(33)}$ & $\begin{array}{l}56 \text { (16 with intrauterine } \\
\text { growth restrictions and } \\
40 \text { controls) }\end{array}$ & $20-34$ & $\begin{array}{l}\text { There was good agreement between the measurements of the ventricular } \\
\text { cardiac volumes using 4D-STIC with VOCAL and 2D- ultrasound with Doppler. }\end{array}$ \\
\hline Messing B et al. (2007) ${ }^{(36)}$ & 100 & $20-40$ & $\begin{array}{l}\text { It was demonstrated that 4D-STIC was simple, highly reproducible, and could } \\
\text { be used for assessing fetal cardiac function. Nomograms for ventricular volume, } \\
\text { stroke volume, and ejection fraction were established by gestational age. The } \\
\text { ratio between RV and LV volumes was } 1.4 \text {. The stroke volume ranged from } 0.78 \\
\text { to } 5.50 \mathrm{~cm}^{3} \text {, and the ejection fraction ranged from } 42.5 \% \text { to } 86.0 \% \text {. }\end{array}$ \\
\hline Molina et al. (2008) $)^{(14)}$ & 140 & $12-34$ & $\begin{array}{l}\text { There was a positive correlation of stroke volume and } \mathrm{CO} \text { of both ventricles } \\
\text { with gestational age. }\end{array}$ \\
\hline Hamill et al. (2009) $)^{(37)}$ & 44 & $19-40$ & VOCAL had good reproducibility for measuring cardiac volumes. \\
\hline $\begin{array}{l}\text { Uittenbogaard et al. } \\
(2010)^{(38)}\end{array}$ & 76 (in vitro) & & $\begin{array}{l}\text { 4D-STIC was shown to be a viable and accurate method for calculating volumes } \\
\text { from } 0.30 \mathrm{~mL} \text {. In vitro, } 4 \mathrm{D}-\mathrm{STIC} \text { combined with the } 3 \mathrm{D} \text { slice method was more } \\
\text { accurate, less time-consuming, and more reliable than VOCAL. }\end{array}$ \\
\hline Rizzo et al. $(2010)^{(34)}$ & $\begin{array}{l}45 \\
\text { (15 with congenital } \\
\text { heart disease and } 30 \\
\text { healthy controls) }\end{array}$ & $19-32$ & $\begin{array}{l}\text { The authors compared ventricular volumes obtained by 4D-STIC with VOCAL } \\
\text { and with sonography-based automated volume count (SonoAVC). The time } \\
\text { necessary to measure volumes using SonoAVC was significantly shorter than } \\
\text { that of the two other methods. However, SonoAVC and VOCAL results were } \\
\text { similar. One limitation of the study was the small sample size. }\end{array}$ \\
\hline Simioni et al. $(2011)^{(39)}$ & 265 & $20-34$ & $\begin{array}{l}\text { Reference curves were constructed for stroke volume, CO, and ejection faction } \\
\text { according to GA. Stroke volume and CO were positively correlated with GA. }\end{array}$ \\
\hline Hamill et al. $(2011)^{(28)}$ & 184 & $19-42$ & $\begin{array}{l}\text { RV diastolic and systolic volumes were larger than LV volumes. LV ejection frac- } \\
\text { tion was larger than RV ejection fraction. Stroke volume and CO increased with } \\
\text { GA, without significant differences between the LV and RV. }\end{array}$ \\
\hline $\begin{array}{l}\text { Schoonderwald et al. } \\
(2012)^{(40)}\end{array}$ & $\begin{array}{l}30 \text { ( } 84 \text { acquired } \\
\text { volumes }-54 \text { excluded } \\
\text { volumes) }\end{array}$ & $20-34$ & $\begin{array}{l}\text { Cardiac volume, stroke volume, and ejection fraction were compared using Simp- } \\
\text { son's and VOCAL methods, and both methods were highly reproducible. The } \\
\text { small sample size was considered a limitation to use 4D-STIC in clinical practice. } \\
\text { *Strict criteria were adopted to include high-quality images of cardiac volumes. }\end{array}$ \\
\hline Simioni et al. $(2012)^{(41)}$ & $\begin{array}{l}216 \text { (108 fetuses of } \\
\text { each sex) }\end{array}$ & $20-24$ & There were no significant sex differences in $\mathrm{CO}$ and ejection fraction. \\
\hline DeKoninck et al. $(2012)^{(42)}$ & 15 & 16,24 , and 24 & $\begin{array}{l}\text { There was good reproducibility of 3D ultrasonography with 4D-STIC for mea- } \\
\text { suring CO when compared to 2D- Doppler ultrasonography. 4D-STIC combined } \\
\text { with SonoAVC and the inversion mode showed higher intra- and interobserver } \\
\text { reproducibility than 4D-STIC combined with VOCAL. }\end{array}$ \\
\hline Hamill et al. $(2013)^{(43)}$ & 34 & $20-36$ & $\begin{array}{l}\text { There was an inverse correlation between ventricular CO and vascular resis- } \\
\text { tance of the umbilical artery using 4D-STIC and VOCAL. }\end{array}$ \\
\hline Rolo et al. $(2015)^{(44)}$ & 200 & $18-33$ & $\begin{array}{l}\text { 4D-STIC with VOCAL was highly reproducible and was used to calculate the } \\
\text { volumes of the IVS by GA. }\end{array}$ \\
\hline Barros et al. $(2015)^{(45)}$ & 371 & $20-33$ & $\begin{array}{l}\text { 4D-STIC and VOCAL was highly reproducible and was used to construct refer- } \\
\text { ence curves for the volumes of the ventricular walls of the fetal heart by GA. }\end{array}$ \\
\hline $\begin{array}{l}\text { Araujo Júnior et al. } \\
(2016)^{(46)}\end{array}$ & 170 & $20-33$ & $\begin{array}{l}\text { 4D-STIC and VOCAL was used to construct reference curves for atrial wall vol- } \\
\text { umes of the fetal heart. }\end{array}$ \\
\hline
\end{tabular}


time-consuming, and more reliable than the two other methods ${ }^{(38)}$.

Rizzo et al. compared the ventricular volumes of 15 fetuses with CHD and 30 fetuses without CHD. The CVs were obtained by 4D-STIC at end-systole and end-diastole and quantified using VOCAL and sonography-based automated volume count (SonoAVC). The time required to measure the ventricular SV was significantly shorter using SonoAVC; however, SonoAVC and VOCAL results were similar. Although it was possible to determine CVs with good intra- and interobserver reproducibility even in fetuses with CHD, the small number of cases was a limitation of this study ${ }^{(34)}$.

Messing et al. used 4D-STIC with VOCAL and inversion mode in 106 fetuses between 21 and 38 weeks of gestation and quantified the ventricular wall mass with good reproducibility, and this parameter was altered in fetuses with CHD. The authors concluded that this technique was important to assess cardiac function in cases involving anatomical and structural changes ${ }^{(36)}$. Simioni et al. constructed reference curves for SV, CO, and EF for 265 fetuses between 20 and 34 weeks of gestation. SV and CO increased with GA, whereas EF remained constant (approximately 0.63) ${ }^{(39)}$. Hamill et al. compared the LV and RV volumes using 4D-STIC and VOCAL and concluded that, although the RV volume was larger than the LV volume, and the LV EF was higher than the RV EF, there were no significant differences in $\mathrm{CO}$ and $\mathrm{SV}^{(28)}$.

Schoonderwaldt et al. measured CVs of 84 fetuses between 20 and 34 weeks of gestation by 4D-STIC and used the Simpson's and VOCAL methods to determine the EDV, ESV, EV, and EF of the LV. The authors compared the two methods and concluded that both presented good reproducibility. However, of the 84 CVs, 54 were excluded because of low-quality images. Consequently, the authors emphasized that the small number of samples with high-quality images limited the use of 4D-STIC in clinical practice. Furthermore, the authors explained that the number of samples was small due to the strict criteria adopted, which considered only the CVs whose endocardial borders were clearly delineated and without shadowing artifacts in all six planes $^{(40)}$.

Simioni et al. performed a cross-sectional study with 216 fetuses (108 females and 108 males) between 20 and 24 weeks of gestation using 4D-STIC and VOCAL. The $\mathrm{CO}$ and EF were calculated using the formulas for $\mathrm{CO}$ for each ventricle, and the EF was determined from the measured volumes. There were significant differences in $\mathrm{CO}$ and EF. The mean values of combined $\mathrm{CO}$, left $\mathrm{CO}$, right $\mathrm{CO}$, right $\mathrm{EF}$, and left $\mathrm{EF}$ in male and female fetuses were $240.07 \mathrm{~mL} / \mathrm{min}, 122.67 \mathrm{~mL} /$ $\mathrm{min}, 123.40 \mathrm{~mL} / \mathrm{min}, 72.84 \%, 67.22 \%, 270.56 \mathrm{~mL} / \mathrm{min}$, $139.22 \mathrm{~mL} / \mathrm{min}, 131.34 \mathrm{~mL} / \mathrm{min}, 70.73 \%$, and $64.76 \%$, respectively ${ }^{(41)}$.
DeKoninck et al. demonstrated that the use of 3D ultrasonography with 4D-STIC for calculating CO had good reproducibility compared to 2D Doppler ultrasonography. Three different techniques were used to determine CO by 3D ultrasonography with 4D-STIC: VOCAL, SonoAVC, and the inversion mode. SonoAVC and the inversion mode presented higher intra- and interobserver reproducibility. The combined $\mathrm{CO}$ values by weight $(\mathrm{mL} /$ $\mathrm{kg} / \mathrm{min}$ ) were $177.2,160.7$, and $174.0 \mathrm{~mL} / \mathrm{kg} / \mathrm{min}$ using VOCAL, SonoAVC, and inversion mode, respectively (all at $p<0.0001)^{(42)}$. However, the sample size of the study was small ( $n=15$, Tab. 1$)$.

Hamill et al. determined the relationship between umbilical vascular impedance and CO using 4D-STIC and VOCAL. The study included 34 fetuses between 20 and 36 weeks of gestation and found that the ventricular volumes were lower in fetuses with increased resistance of the umbilical artery when compared to normal fetuses with a relatively higher decrease in LV volume ${ }^{(43)}$.

Rolo et al. measured the volume of the interventricular septum (IVS) of 200 fetuses between 18 and 33 weeks gestation. The mean IVS values ranged from $0.13 \pm 0.03 \mathrm{~cm}^{3}$ to $1.33 \pm 0.37 \mathrm{~cm}^{3(44)}$. Barros et al. calculated the cardiac wall volumes in 371 fetuses between 20 and 33 weeks gestation and created reference curves using 4D-STIC and VOCAL $^{(45)}$. In both studies, the authors demonstrated that the technique presented good intra- and interobserver reproducibility.

Araujo Júnior et al. calculated atrial wall volumes in 170 fetuses between 20 and 33 weeks and 6 days of gestation using 4D-STIC and VOCAL. The mean right atrium volume varied from $0.45 \pm 0.16 \mathrm{~cm}^{3}$ to $2.17 \pm 0.62 \mathrm{~cm}^{3}$, and the mean left atrium volume ranged from $0.54 \pm 0.21 \mathrm{~cm}^{3}$ to $2.17 \pm 0.3 \mathrm{~cm}^{3(46)}$.

\section{Conclusion}

Since 2004, several studies demonstrated a positive correlation of ventricular and atrial volumes with GA using 4D-STIC and VOCAL. Similarly, the CO calculated using these methods showed a positive correlation with GA, and $\mathrm{RV}$ volumes were larger than LV volumes. The retrieved studies demonstrated that 4D-STIC and VOCAL had good reproducibility to measure cardiac volumes and developed reference curves for this parameter by GA. Therefore, 4D-STIC and VOCAL are crucial for evaluating cardiac function parameters, including end-systolic volume, CO, and EF.

\section{Conflict of interest}

Authors do not report any financial or personal connections with other persons or organizations, which might negatively affect the contents of this publication and/or claim authorship rights to this publication. 


\section{References}

1. CDC - Centers for Disease and Prevention. Congenital Heart Defects [cited 2019 May 12]. Available from: http://www.cdc.gov/heartdefects/.

2. Hoffman JI, Kaplan S: The incidence of congenital heart disease. J Am Coll Cardiol 2002; 39: 1890-1900.

3. Nelle M, Raio L, Pavlovic M, Carrel T, Surbek D, Meyer-Wittkopf M: Prenatal diagnosis and treatment planning of congenital heart defectspossibilities and limits. World J Pediatr 2009; 5: 18-22.

4. Eurocat - European Surveillance of congenital anomalies [cited 2019 May 12]. Available from: http://www.eurocat-network.eu/statisticalmonitoring-2009.

5. Allan L: Impact of prenatal diagnosis on the paediatric management of heart defects. Fetal Mater Med Rev 2004; 15: 327-341.

6. Donofrio MT, Skurow-Todd K, Berger JT, McCarter R, Fulgium A, Krishnan A et al.: Risk-stratified postnatal care of newborns with congenital heart disease determined by fetal echocardiography. J Am Soc Echocardiogr 2015; 28: 1339-1349.

7. Słodki M, Respondek-Liberska M, Pruetz JD, Donofrio MT: Fetal cardiology: changing the definition of critical heart disease in the newborn. J Perinatol 2016; 36: 575-580.

8. Van Mieghem T, Hodges R, Jaeggi E, Ryan G: Functional echocardiography in the fetus with non-cardiac disease. Prenat Diagn 2014; 34: 23-32.

9. Bravo-Valenzuela NJ, Peixoto AB, Nardozza LM, Souza AS, Araujo Júnior E: Applicability and technical aspects of two-dimensional ultrasonography for assessment of fetal heart function. Med Ultrason 2017; 19: 94-101.

10. Crispi F, Gratacós E: Fetal cardiac function: technical considerations and potential research and clinical applications. Fetal Diagn Ther 2012; 32: 47-64.

11. Gardiner HM: Foetal cardiac function: assessing new technologies. Cardiol Young 2014; 24 Suppl 2: 26-35.

12. Barker PC, Houle H, Li JS, Miller S, Herlong JR, Camitta MG: Global longitudinal cardiac strain and strain rate for assessment of fetal cardiac function: novel experience with velocity vector imaging. Echocardiography 2009; 26: 28-36.

13. Miranda JO, Cerqueira RJ, Ramalho C, Areias JC, Henriques-Coelho T: Fetal cardiac function in maternal diabetes: a conventional and speckletracking echocardiographic study. J Am Soc Echocardiogr 2018; 31: 333-341.

14. Molina FS, Faro C, Sotiriadis A, Dagklis T, Nicolaides KH: Heart stroke volume and cardiac output by four-dimensional ultrasound in normal fetuses. Ultrasound Obstet Gynecol 2008; 32: 181-187.

15. Simioni C, Nardozza LM, Araujo Júnior E et al.: Fetal cardiac function assessed by spatio-temporal image correlation. Arch Gynecol Obstet 2011; 284: 253-260.

16. Tei $\mathrm{C}$, Ling LH, Hodge DO, Bailey KR, Oh JK, Rodeheffer RJ et al.: New index of combined systolic and diastolic myocardial performance: a simple and reproducible measure of cardiac function - a study in normals and dilated cardiomyopathy. J Cardiol 1995; 26: 357-366.

17. Figueroa H, Silva MC, Kottmann C, Viguera S, Valenzuela I, Hernandez-Andrade E et al.: Fetal evaluation of the modified-myocardial performance index in pregnancies complicated by diabetes. Prenat Diagn 2012; 32: 943-948.

18. Bhorat IE, Bagratee JS, Pillay M, Reddy T: Use of the myocardial performance index as a prognostic indicator of adverse fetal outcome in poorly controlled gestational diabetic pregnancies. Prenat Diagn 2014, 34: 1301-1306.

19. Peixoto AB, Bravo-Valenzuela NJ, Martins WP, Mattar R, Moron AF, Araujo Júnior E: Reference ranges for the left ventricle modified myocardial performance index, respective time periods, and atrioventricular peak velocities between 20 and $36+6$ weeks of gestation. J Matern Fetal Neonatal Med 2019; 2: 1-10. Doi: 10.1080/14767058.2019.1609933.

20. Cruz-Lemini M, Crispi F, Valenzuela-Alcaraz B, Figueras F, Sitges M, Gómez O et al.: Value of annular M-mode displacement vs tissue Doppler velocities to assess cardiac function in intrauterine growth restriction. Ultrasound Obstet Gynecol 2013; 42: 175-181.

21. Messing B, Gilboa Y, Lipschuetz M, Valsky DV, Cohen SM, Yagel S: Fetal tricuspid annular plane systolic excursion (f-TAPSE): evaluation of fetal right heart systolic function with conventional M-mode ultrasound and spatiotemporal image correlation (STIC) M-mode. Ultrasound Obstet Gynecol 2013; 42: 182-188.

22. Tedesco GD, de Souza Bezerra M, Barros FSB, Martins WP, Nardozza LMM, Mattar R et al.: Fetal heart function by tricuspid annular plane systolic excursion and ventricular shortening fraction using STIC Mmode: reference ranges and validation. Am J Perinatol 2017; 34: 1354 1361.

23. Mielke G, Benda N: Cardiac output and central distribution of blood flow in the human fetus. Circulation 2001; 103: 1662-1668.

24. Gagnon C, Bigras JL, Fouron JC, Dallaire F: Reference values and $\mathrm{Z}$ scores for pulsed-wave Doppler and M-mode measurements in fetal echocardiography. J Am Soc Echocardiogr 2016; 29: 448-460.e9.

25. Mao YK, Zhao BW, Zhou L, Wang B, Chen R, Wang SS: Z-score reference ranges for pulsed-wave Doppler indices of the cardiac outflow tracts in normal fetuses. Int J Cardiovasc Imaging 2019; 35: 811-825.

26. Rocha LA, Rolo LC, Nardozza LM, Tonni G, Araujo Júnior E: Z-score reference ranges for fetal heart functional measurements in a large brazilian pregnant women sample. Pediatr Cardiol 2019; 40: 554-562.

27. Huhta JC: Fetal congestive heart failure. Sem Fetal Neonatal Med 2005; 10: 542-552.

28. Hamill N, Yeo L, Romero R, Hassan SS, Myers SA, Mittal P et al.: Fetal cardiac ventricular volume, cardiac output, and ejection fraction determined with 4-dimensional ultrasound using spatiotemporal image correlation and virtual organ computer-aided analysis. Am J Obstet Gynecol 2011; 205: 76.e1-10.

29. Tongsong T, Wanapirak C, Piyamongkol W, Sirichotiyakul S, Tongprasert F, Srisupundit K et al.: Fetal ventricular shortening fraction in hydrops fetalis. Obstet Gynecol 2011; 117: 84-91.

30. DeVore GR, Falkensammer P, Sklansky MS, Platt LD: Spatio-temporal image correlation (STIC): new technology for evaluation of the fetal heart. Ultrasound Obstet Gynecol 2003; 22: 380-387.

31. Viñals F, Ascenzo R, Naveas R, Huggon I, Giuliano A: Fetal echocardiography at $11+0$ to $13+6$ weeks using four-dimensional spatiotemporal image correlation telemedicine via an Internet link: a pilot study. Ultrasound Obstet Gynecol 2008; 31: 633-638.

32. Gonçalves LF, Lee W, Espinoza J, Romero R: Examination of the fetal heart by four-dimensional (4D) ultrasound with spatio-temporal image correlation (STIC). Ultrasound Obstet Gynecol 2006; 27: 336-348.

33. Rizzo G, Capponi A, Cavicchioni O, Vendola M, Arduini D: Fetal cardiac stroke volume determination by four-dimensional ultrasound with spatio-temporal image correlation compared with two-dimensional and Doppler ultrasonography. Prenat Diagn 2007; 27: 1147-1150.

34. Rizzo G, Capponi A, Pietrolucci ME, Arduini D: Role of sonographic automatic volume calculation in measuring fetal cardiac ventricular volumes using 4-dimensional sonography: comparison with virtual organ computer-aided analysis. J Ultrasound Med 2010; 29: 261-270.

35. Bhat AH, Corbett VN, Liu R, Carpenter ND, Liu NW, Wu AM et al.: Fetal ventricular mass determination on three-dimensional echocardiography: studies in normal fetuses and validation experiments. Circulation 2004; 110: 1054-1060.

36. Messing B, Cohen SM, Valsky DV, Rosenak D, Hochner-Celnikier D, Savchev $\mathrm{S}$ et al.: Fetal cardiac ventricle volumetry in the second half of gestation assessed by 4D ultrasound using STIC combined with inversion mode. Ultrasound Obstet Gynecol 2007; 30: 142-151.

37. Hamill N, Romero R, Hassan SS, Lee W, Myers SA, Mittal P et al.: Repeatability and reproducibility of fetal cardiac ventricular volume calculations using spatiotemporal image correlation and virtual organ computer-aided analysis. J Ultrasound Med 2009; 28: 1301-1311.

38. Uittenbogaard LB, Haak MC, Peters RJ, van Couwelaar GM, Van Vugt JM: Validation of volume measurements for fetal echocardiography using four-dimensional ultrasound imaging and spatiotemporal image correlation. Ultrasound Obstet Gynecol 2010; 35: 324-331.

39. Simioni C, Nardozza LM, Araujo Júnior E, Rolo LC, Zamith M, Caetano AC et al.: Heart stroke volume, cardiac output, and ejection fraction in 265 normal fetus in the second half of gestation assessed by 4D ultrasound using spatio-temporal image correlation. J Matern Fetal Neonatal Med 2011; 24: 1159-1167.

40. Schoonderwaldt EM, Groenenberg IA, Hop WC, Wladimiroff JW, Steegers EA: Reproducibility of echocardiographic measurements of 
human fetal left ventricular volumes and ejection fractions using fourdimensional ultrasound with the spatio-temporal image correlation modality. Eur J Obstet Gynecol Reprod Biol 2012; 160: 22-29.

41. Simioni C, Araujo Júnior E, Martins WP, Rolo LC, Rocha LA, Nardozza LM et al.: Fetal cardiac output and ejection fraction by spatio-temporal image correlation (STIC): comparison between male and female fetuses. Rev Bras Cir Cardiovasc 2012; 27: 275-282.

42. DeKoninck P, Steenhaut P, Van Mieghem T, Mhallem M, Richter J, Bernard P et al.: Comparison of Doppler-based and three-dimensional methods for fetal cardiac output measurement. Fetal Diagn Ther 2012; 32: 72-78.

43. Hamill N, Romero R, Hassan S, Lee W, Myers SA, Mittal P et al.: The fetal cardiovascular response to increased placental vascular impedance to flow determined with 4-dimensional ultrasound using spatiotemporal image correlation and virtual organ computer-aided analysis. Am J Obstet Gynecol 2013; 208: 153.e1-13.
44. Rolo LC, Santana EF, da Silva PH, Costa Fda S, Nardozza LM, Tonni G et al.: Fetal cardiac interventricular septum: volume assessment by 3D/4D ultrasound using spatio-temporal image correlation (STIC) and virtual organ computer-aided analysis (VOCAL). Matern Fetal Neonatal Med 2015; 28: 1388-1393.

45. Barros FS, Rolo LC, Rocha LA, Martins WP, Nardozza LM, Moron AF et al.: Reference ranges for the volumes of fetal cardiac ventricular walls by three-dimensional ultrasound using spatiotemporal image correlation and virtual organ computer-aided analysis and its validation in fetuses with congenital heart diseases. Prenat Diagn 2015; 35: 65-73.

46. Araujo Júnior E, Novoa Y Novoa VA, Barros FS, Rocha LA, Peixoto AB, Martins WP et al.: Reference values for the volumes of foetal heart atrial wall by three-dimensional ultrasound using STIC and VOCAL methods between 20w0d and 33w6d weeks of gestation. J Matern Fetal Neonatal Med 2016; 29: 3076-3083. 